\title{
HIGH INJECTION EFFECTS ON SOLAR CELL PERFORMANCES
}

\author{
P. MIALHE AND B. AFFOUR \\ Centre d'Etudes Fondamentales, Université de Perpignan, 66860 PERPIGNAN Cedex, France. \\ K. EL-HAJJ* AND A. KHOURY \\ Laboratoire de Physique, Faculté des Sciences, Université Libanaise, B.P. 90656 JDEID, Liban. \\ (Received June 17, 1994; in final form July 20, 1994)
}

Experiments are performed on solar cells under concentrated sunlight in order to explore fundamental physical processes with high injection conditions. Saturation effects are observed on the cell open circuit voltage and on the extracted values of the recombination current. A large decrease of the initial decay of the transient voltage have been measured. High injection effects are shown to be correlated with the increase of recombination current in the space charge region together with an increase of the emitterbase coupling.

\section{INTRODUCTION}

An approach to achieve significant cost reduction of photovoltaic energy conversion systems consists of increasing their output power per $\mathrm{cm}^{2}$, obtained by concentrating the incident sunlight onto cells. There are two basic effects induced by high levels of illumination that degrade performances of solar cells. One effect is the inherent increase in the operating temperature $\mathrm{T}$ of the solar cell which leads to cool the cell and introduces combined photovoltaic-solar-thermal systems. ${ }^{1}$ The other effect is the increase in excess minority carrier density to a value comparable to the thermal equilibrium value of the majority carrier density. Thus, high injection conditions appear and the fundamental physical processes of carrier transport in the cell are modified and not well understood until now. The strength of the p-n coupling between the excess carrier concentrations at the junction on both its sides becomes quite important ${ }^{2}$ : the rate of recombination processes becomes an increasing function of carrier concentrations, ${ }^{3}$ and losses increase.

There are two main purposes of this work. First, we present experimental results that are saturation and fast transient measurements to explore solar cell performances and limitations with high injection operating conditions. Second, a modelling study is performed that suggests, in terms of space charge recombination current, a physical interpretation of the observed effects.

\section{EXPERIMENTS}

The solar cells we considered in this work were high-performance, commercial blue solar cells for terrestrial use: the emitter region is made fairly thin $(0.1-0.2$ 
$\mu \mathrm{m})$ of $\mathrm{n}+$ type formed by low-energy ion implantation, the emitter surface is oxide passivated to reduce surface recombination, and grid contact recombination is lowered by reducing the metal silicon area. Fresnel lenses are used to realize light concentration. Measurements are made possible at a constant temperature by using a data acquisition system including a computer. A load may be derived by a generator and open circuited with a fast switch (characteristic switching time: $30 \mathrm{~ns}$ ). The computer acquires and stores the values (I, V) for 100 points of the whole characteristic within less than $1 \mathrm{~ms}$ or monitors the transient voltage ${ }^{4}$ when operating with the pulse generator. From the I-V characteristic, it is possible to determine the cell parameters. Using the open circuit voltage transient curve (Fig. (1)), a numerical procedure allows the determination of the decay time $\tau_{\mathrm{oc}}$.

Figure (2) displays the variation of the open circuit voltage $\left(\mathrm{V}_{\mathrm{oc}}\right)$ against the light concentration factor $\mathrm{C}$ (the illumination increases from one sun to $\mathrm{C}$ suns); measurements have been possible at a constant temperature by using the rapid data acquisition system. We get the well-known ${ }^{5}$ saturation of $\mathrm{V}_{\mathrm{oc}}$, which was attributed to the Dember potential ${ }^{6}$ : the theory was developed in terms of the product of carrier concentrations but the variation in photovoltage with light intensity cannot be calculated. Later, ${ }^{3}$ limits on the open circuit voltage were related to intrinsic Auger processes without an interpretation of this saturation effect, which was referred to as a high injection effect. Our experiments were made with a low-doped $\left(2.10^{15} \mathrm{~cm}^{-3}\right)$ base solar cell to allow it to reach high injection conditions

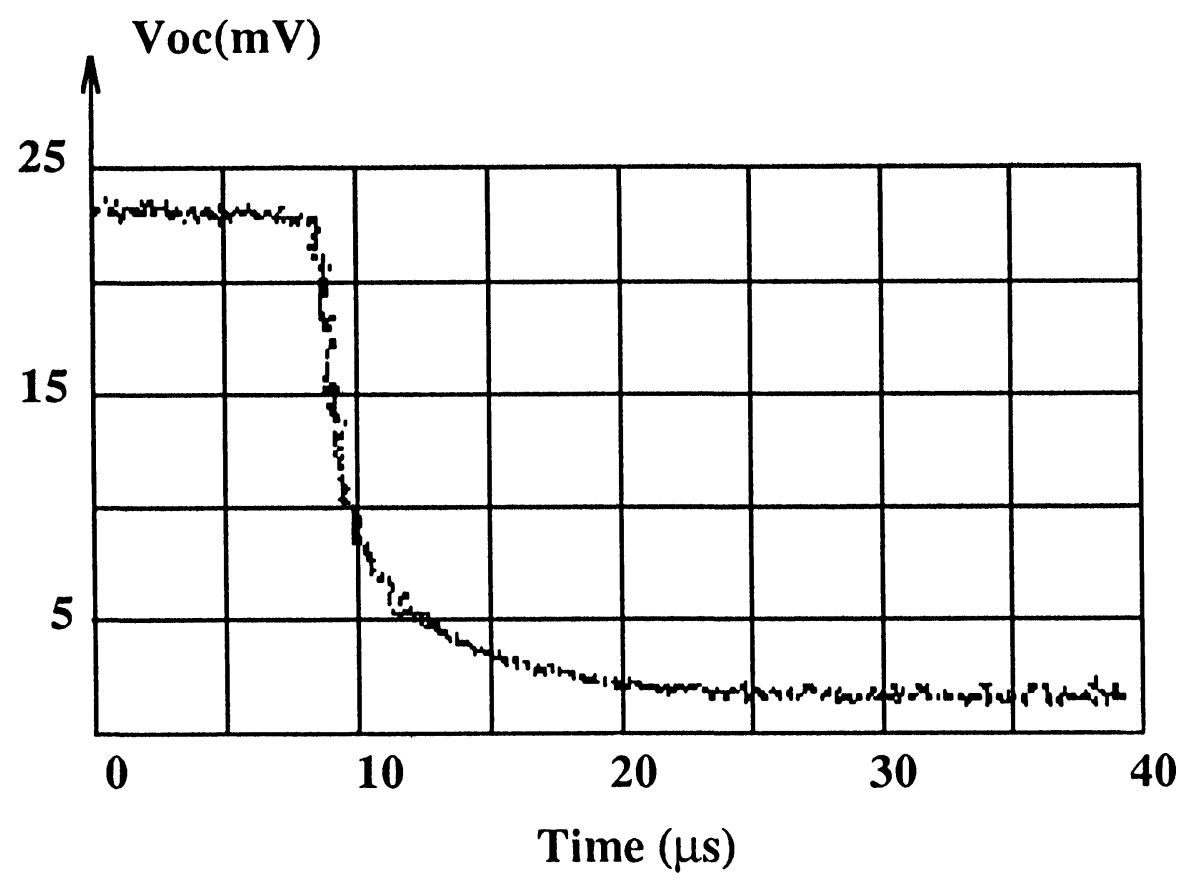

FIGURE 1 The open circuit voltage decay curve. 


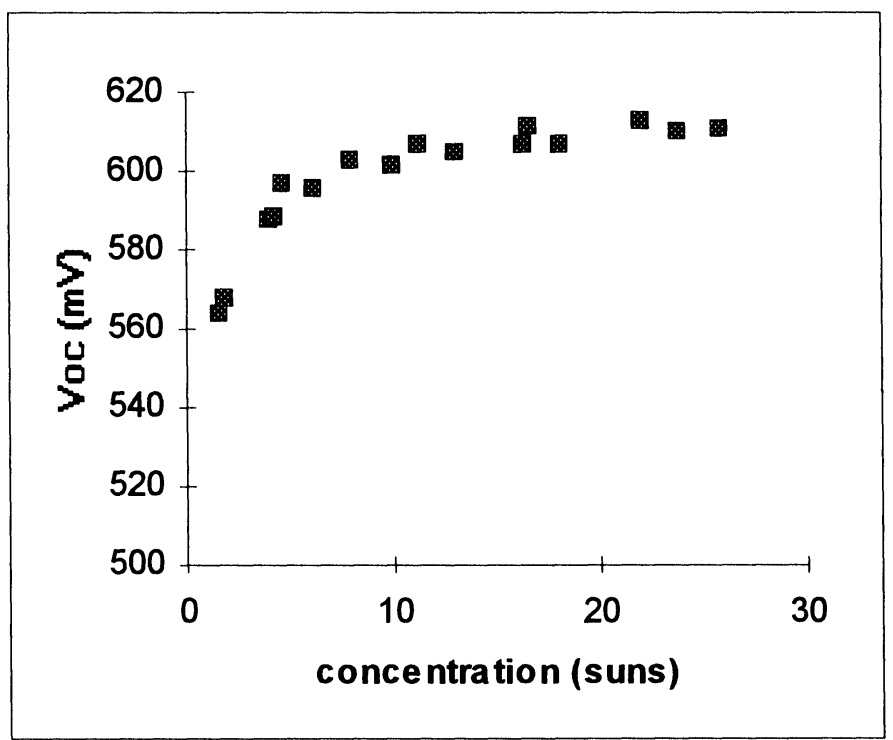

FIGURE 2 The open circuit voltage as a function of light concentration factor $\mathrm{C}$.

with an illumination level of 10 suns. In such a case, both Auger recombination rates and Dember voltage drops are insignificant. ${ }^{6}$

Figure (3) displays a rather important effect that has not been previously reported. A large decrease of the decay time in the linear first stage of the transient voltage is observed when the illumination level is increased. For each measurement, a constant illumination level $\mathrm{C}$ is preserved during all the transient event.

This effect may be understood from general $p$-n junction theory. The total current flow is zero in open circuit conditions and results (at the junction) in injected charges into the base and the emitter. It leads to the classical ${ }^{8,9}$ current boundary condition (also called emitter base coupling conditions), which relates the excess minority carrier densities $n(x, t)$ and $p(x, t)$ in the two sides of the junction (located at $\mathrm{x}=0)$ :

$\mathrm{D}_{\mathrm{n}} \cdot \delta \mathrm{n}(\mathrm{x}, \mathrm{t}) / \delta \mathrm{x}-\left.\mathrm{D}_{\mathrm{p}} \cdot \frac{\delta \mathrm{p}(\mathrm{x}, \mathrm{t})}{\delta \mathrm{x}}\right|_{\mathrm{x}}=0$

$n(x, t) / p(x, t)=n_{o} / p_{o}$

where $D_{n}$ and $D_{p}$ are the minority carrier diffusion coefficients in the base and in the emitter, and $n_{o}$ and $p_{o}$ are the thermal concentrations of minority carriers.

The decay rate of the carriers at the junction in the emitter is more rapid than in the base (since the emitter is highly doped, compared to the base), that makes necessary (see the coupled equations (1) and (2)) an increase in the reverse-base current in the initial stage of the transient curve. As a consequence, the decay time of the open circuit voltage transient curve is lower in the initial stage. Further, results in Figure (3) display an experimental evidence of the increase of the emitter- 


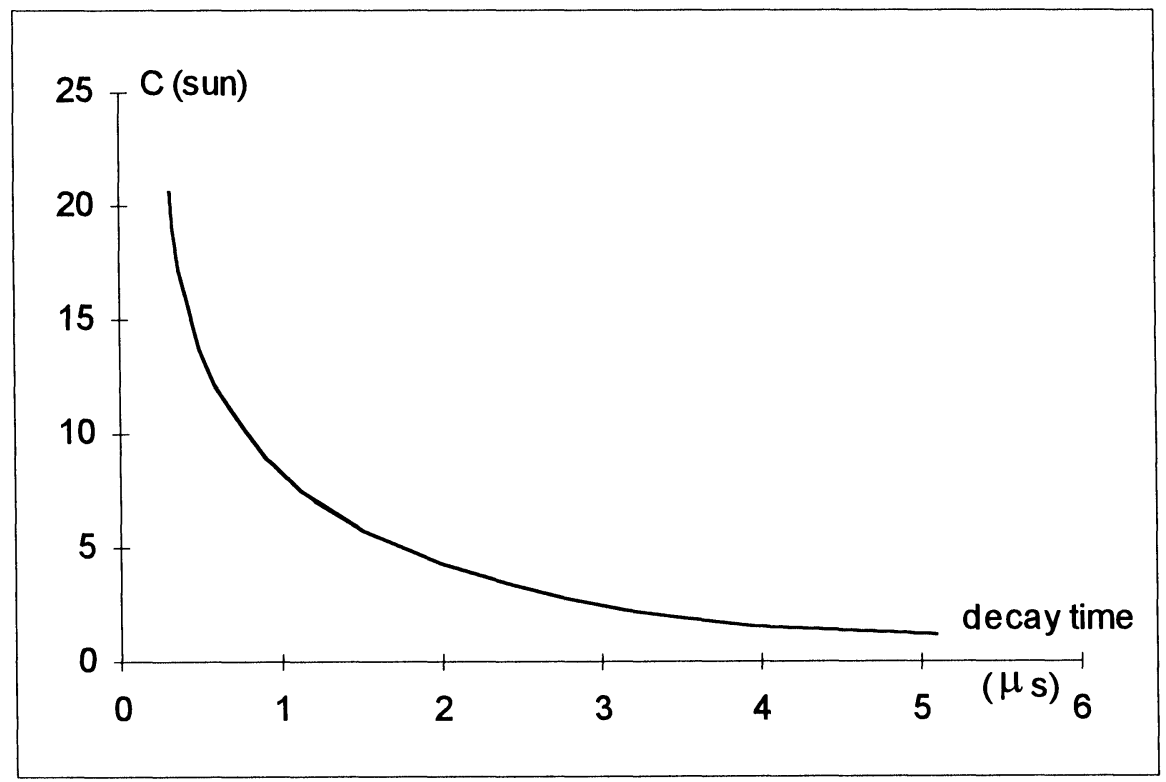

FIGURE 3 The time constant $\tau_{\mathrm{c},}$ of the linear decay of the transient open circuit voltage.

base coupling with an increase of the light concentration factor $\mathrm{C}$. This was foreseen in a theoretical work ${ }^{10}$ on the emitter recombination effect in a $\mathrm{p}-\mathrm{n}$ junctions.

This experimental procedure eliminates ${ }^{9}$ the uncertainties due to junction capacitance effects, since the high illumination level is not varied during the measurements.

\section{MODELLING AND RESULTS}

High injection effects, pointed out by experiments described above, are related to the high level of minority carrier concentration obtained in the base. As a consequence, carrier transport processes are modified and should be determined in order to assert our results. The description of current-voltage characteristics by using a double exponential model ${ }^{11}$ enables this description.

Modelling studies ${ }^{12.13}$ have shown that the I-V characteristic can be fitted using the equation

$I=I_{p h}-V_{d} / R_{s h}-\sum_{i=1,2} I_{o i} \cdot\left(\exp \left(B_{i} \cdot V_{d}\right)-1\right)$

where $\mathrm{V}_{\mathrm{d}}=\mathrm{V}+\mathrm{I} \cdot \mathrm{R}_{\mathrm{s}}, \mathrm{B}_{1}=\mathrm{q} / \mathrm{KT}, \mathrm{B}_{2}=\mathrm{B}_{1} / 2$.

$I_{p h}$ is the photocurrent due to incident photons and $I_{01}$ and $I_{02}$ are the dark saturation currents of the two diodes in the equivalent circuit. This double-diode model allows one to differentiate two main processes in the solar cell; diffusionrecombination in the bulk and the recombination in the space charge region, cor- 


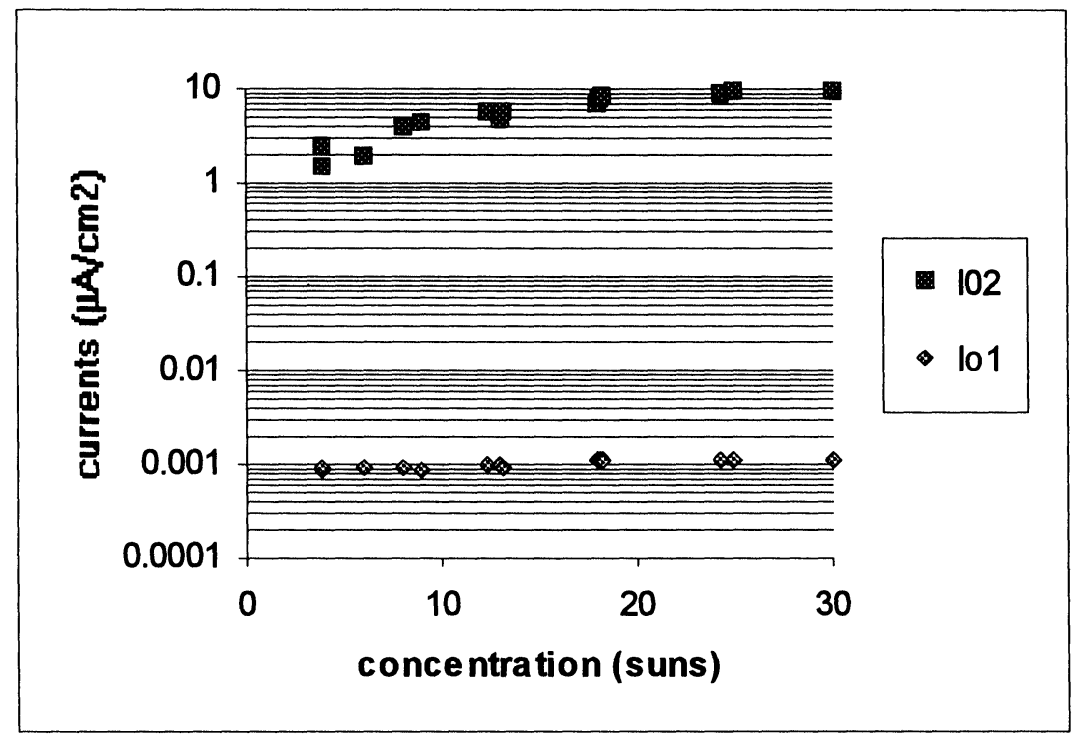

FIGURE 4 The cell saturation currents as a function of light concentration factor.

related to $I_{o 1}$ and $I_{02}$ respectively. $R_{s}$ and $R_{s h}$ are the series and shunt resistances. A computer procedure ${ }^{14}$ leads to extract the values of the physical parameters $I_{p h}$, $\mathrm{I}_{\mathrm{o} 1}, \mathrm{I}_{\mathrm{o} 2}, \mathrm{R}_{\mathrm{s}}$, and $\mathrm{R}_{\mathrm{sh}}$ for an exact correspondence between the calculated and the experimental characteristics.

When varying light concentration from 1 to 25 suns, we get the variations of saturation currents $I_{01}$ and $I_{02}$ shown in Figure (4) against the light concentration factor C. No correlation appears between $I_{o 1}$ and the large increase of C. Since $I_{01}$ is related to material parameters by the relation:

$\left.I_{o 1}=q\left(n_{i}^{2} / N_{E} \cdot\left(D_{p} / \tau_{n}\right)^{1 / 2}+n_{i}^{2} / N_{B} \cdot D_{n} / \tau_{p}\right)^{1 / 2}\right)$

where $n_{i}$ is the intrinsic carrier concentration, $N_{E}$ and $N_{B}$ are the emitter and base doping levels, $\tau_{\mathrm{p}}$ and $\tau_{\mathrm{n}}$ are the emitter and base lifetime of carriers, and Dp and Dn the diffusion coefficients. This result shows that intrinsic cell parameters are not modified when the injection level is increased. To the contrary, the large increase in the space charge recombination current $I_{02}$ makes clear that high injection effects are correlated to a modification of carrier transport phenomena in the space charge region. An increase in silicon cell efficiency has been obtained by the inclusion of local substructure ${ }^{15,16}$ near the p-n junction with low-high interfaces. These interfaces create strong electric fields drifting carriers, and a lowering of space charge and emitter base coupling effects.

\section{CONCLUSION}

We have performed experiments with operating solar cells under high injection conditions. Both a saturation of the open circuit voltage and a decrease in the 
transient decay time in open circuit conditions were obtained. Experiments were done on a low-doped base silicon solar cell so that Auger recombination processes and Dember voltage drops were not significant. The analysis of the variations of the cell parameters have shown that the recombination current in the space charge region increased with the injection level without modification of bulk diffusion and recombination processes. This work points out that the observed high injection effects are related to an increase of the emitter-base coupling, correlated with recombination processes in the space charge region.

\section{REFERENCES}

1. D.J. Mbewe, H.C. Card and D.C. Card, Solar Energy, 35, 247-58 (1985).

2. S.C. Jain, E.L. Heasell and D.J. Roulston, Prog. Quant. Electron., 11, 105-204 (1987).

3. M.A. Green, IEEE Trans. on Electron Devices, ED-31, 671-78 (1984).

4. J.M. Salagnon, P. Mialhe and F. Pelanchon, Proc. Intern. Conf. Signals \& Systems (Al-Ain Jan. 29-31), 4, p.11-17 (1990).

5. J.E. Parrott, IEEE Trans. on Electron Devices, ED-21, 89-93 (1974).

6. P. Mialhe, S. Mouhammad, F. Pelanchon and A. Haydar, Modelling, Simulation \& Control, 21, 25-28 (1989).

7. V.K. Tewary and S.C. Jain, Adv. Electron. Electr. Phys., 67, 329-414 (1986).

8. S.C. Jain and U.C. Ray, J. Appl. Phys., 54, 2079-85 (1983).

9. K. Joardar, R.C. Dondero and D.K. Schroder, Solid-State Electron., 32, 479-83 (1989).

10. S.C. Jain and Muralidharan, Solid-State Elect., 24, 1147-54 (1981).

11. M. Wolf, G.T. Noel and R.J. Stirn, IEEE Trans. on Electron Dev., ED-24, 419-28 (1977).

12. J.P. Charles, I.M. Alaoui, G. Bordure and P. Mialhe, Rev. Phys., Appl., 19, 851-57 (1984)

13. G.L. Araujo, E. Sanchez and J. Marti, Solar Cells, 5, 199-204 (1982).

14. J.P. Charles, I.M. Alaoui, G. Bordure and P. Mialhe, Solid-State Electron., 28, 807-20 (1985).

15. J. Li, M. Chang, Z. Zhu, Y. Li, X. Xu, P. Wang, Z. Shang, Z. Yang, R. Zhur and X. Cao, Appl Phys. Lett. 60, 2240-42 (1992).

16. Z.T. Kuznicki, J.C. Muller and Lipinski, Proc. 23rd IEEE Photovoltaic Spe. Conf., Louisville 10-14 May 1993 (to be published). 

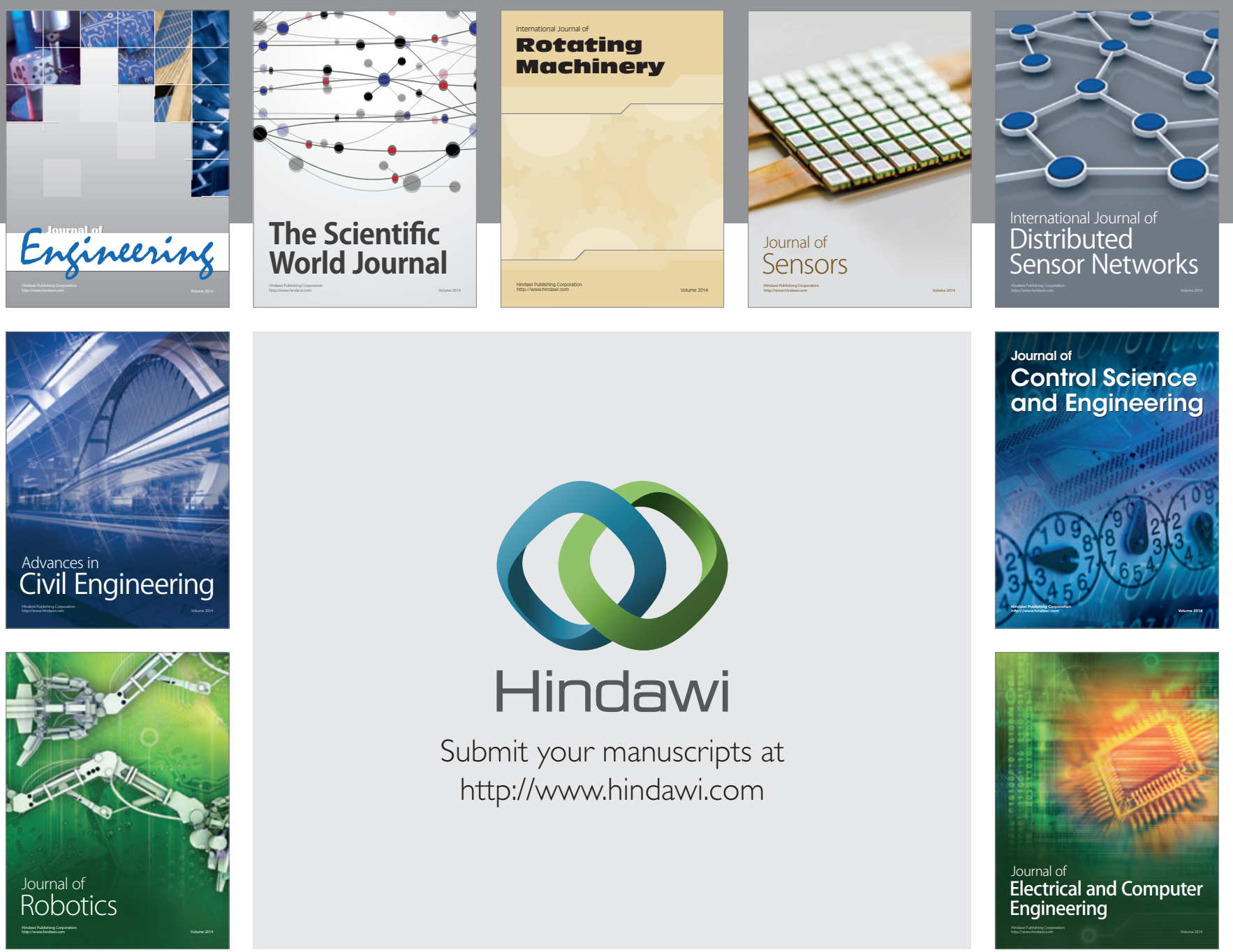

Submit your manuscripts at

http://www.hindawi.com
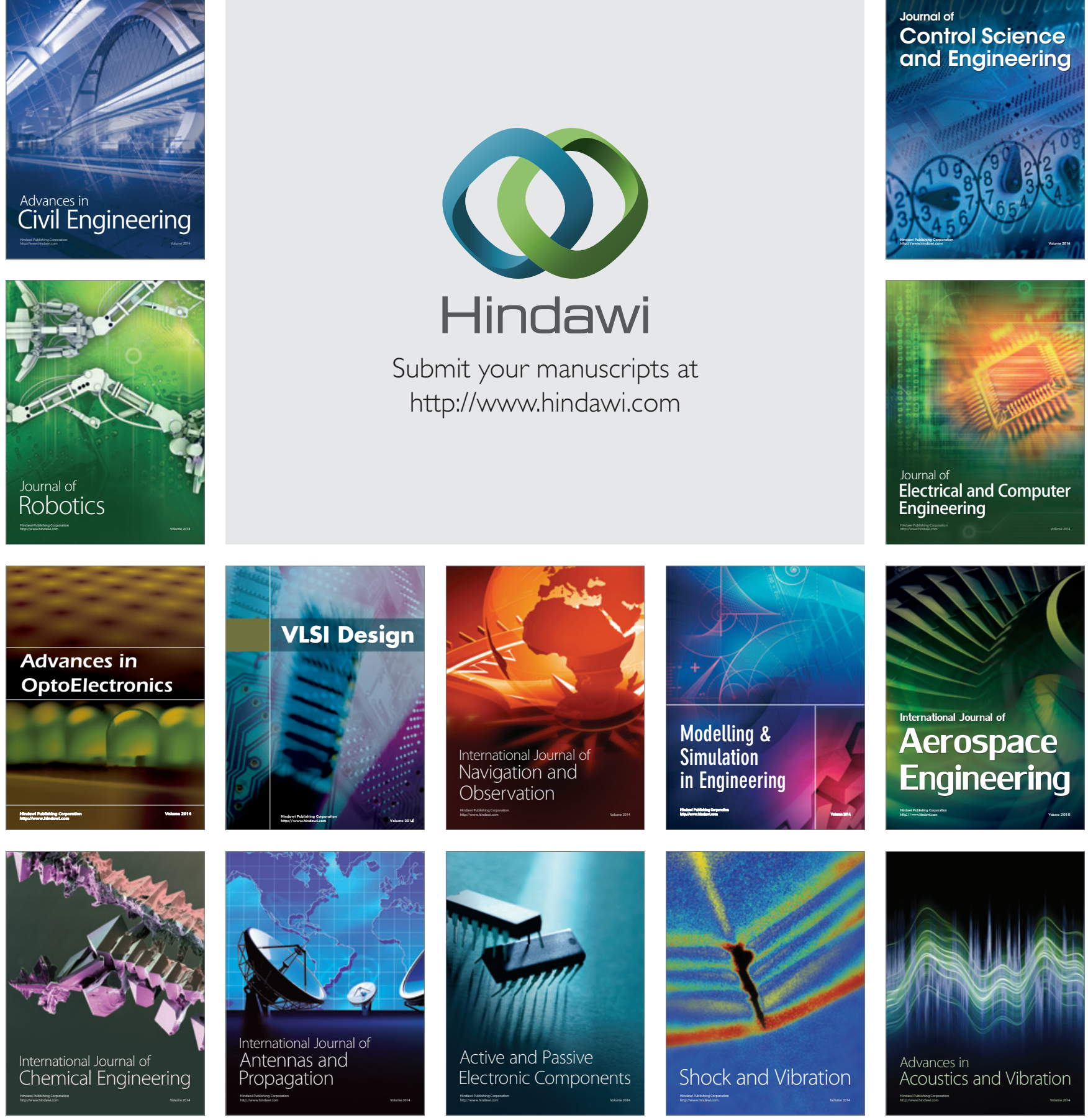